\title{
Development and Testing of Runner and Conical Basin for Gravitational Water Vortex Power Plant
}

\author{
Subash Dhakal, Susan Nakarmi, Pikam Pun, Arun Bikram Thapa, Tri Ratna Bajracharya \\ Energy Systems Planning and Analysis Unit, Centre for Energy Studies, IOE, TU, Pulchowk, Lalitpur, Nepal \\ Corresponding Email: triratna@ioe.edu.np
}

\begin{abstract}
The Terai region in Nepal has water resources with very low head and medium to high discharge conditions. Hence, the people of the Terai region are not being able to utilize the water resources available near them due to the limitation of technology. This study is intended to serve the purpose of further research of ultra-low head gravitational water vortex turbines useful for power generation in the Terai region.

Gravitational water vortex turbine is an ultra-low head turbine which can operate in as low head as $0.7 \mathrm{~m}$ with similar yield as conventional hydroelectric turbines characterized with positive environmental yield. This study has been carried out in two phases. In the first phase, two different turbines are to designed and fabricated and the performance characteristics of the new turbine are to be compared with that of the installed turbine. The second phase includes the design and fabrication of the conical basin. Experimental tests will be carried out and the performance of the system with the use of a conical basin will compared with that of the system using the cylindrical basin. A site testing also has been carried out to ensure the performance of system.
\end{abstract}

Keywords: vortex, irrotational, inviscid, vortex strength, orifice, CATIA V5, stress analysis, prony brake system, tachometer, cylindrical basin, conical basin

\section{Introduction}

\section{Design of Runner}

\section{Background}

The water vortex striking the turbine blades has been modeled as a jet of water striking the turbine blades like in cross-flow or other impulse turbines. Taking the inlet jet angle to be $16^{\circ}$ [10] and assuming no outlet whirl velocity, the design proceeds with the calculation of the inlet and outlet blade angles using velocity triangles.

\section{Assumptions}

Certain valid assumptions were made for the design of the model turbine. They are listed below:

- Head and pressure losses are negligible.

- The velocity with which the water strikes the runner is uniform along the length of the turbine.

- The flow in the water vortex is inviscid and irrotational. 


\section{Vortex theory for runner design}

In a water vortex, water swirls around an empty core (vortex center) of decreasing radius. A water vortex can be defined as a flow pattern with streamlines having concentric circles. In reality, since all fluids have viscosity, no flow is truly irrotational. However, flows can be successfully studied by assuming them to be inviscid and irrotational because of the negligible viscous effects [4].

In a free (irrotational) vortex, fluid particles do not rotate as they translate in circular paths around the vortex center [4].

For an irrotational vortex, the radial velocity $(\mathrm{Vr})$ is zero, while the tangential velocity $\left(\mathrm{V}_{\Theta}\right)$ is given by:

$$
V_{\Theta}=K \div(2 * \pi * r)
$$

Where, $\mathrm{K}$ is the strength of vortex and is defined as volume flow rate per unit depth [4].

$$
K=Q \div h
$$

\section{Blade Design}

Let $\beta 1=16^{\circ}, \beta 2=90^{\circ}, \mathrm{ID}=100 \mathrm{~mm}, \mathrm{OD}=180 \mathrm{~mm}$ for initial design. The head $(\mathrm{H})$ was measured to be $0.78 \mathrm{~m}$ while the flow rate was calculated was $\mathrm{Q}=8.63 \mathrm{l} / \mathrm{s}$ (of test rig used for experiment). Turbine depth from the upper surface of vortex was measured to be $\mathrm{h}=0.735 \mathrm{~m}$. At this depth, the radius of vortex was calculated to be $r=12 \mathrm{~mm}$ by substituting in the parabolic trend line.

Turbine speed for an impulse type turbine is given by [6]:

$$
N t=39 \times \sqrt{H} \div \mathrm{OD}
$$

Therefore, $\mathrm{Nt}=191 \mathrm{rpm}$, which is the design speed.

\section{Calculation of vortex velocity components}

$$
\begin{aligned}
& \mathrm{Vr}=0 \\
& K=Q \div h=0.01174 \mathrm{~m}^{2} / \mathrm{s} \\
& V \theta=K \div(2 * \pi * r)=0.1558 \mathrm{~m} / \mathrm{s}
\end{aligned}
$$

\section{Calculations at inlet}

$$
\begin{aligned}
& V 1=\sqrt{ }(2 * g * H)=3.91 \mathrm{~m} / \mathrm{s} \\
& V t=V 1+V \Theta=4.068 \mathrm{~m} / \mathrm{s} \\
& V w 1=\pi \times O D \times N t \div 60=1.803 \mathrm{~m} / \mathrm{s} \\
& V f 1=V t \times \sin \beta 1=1.121 \mathrm{~m} / \mathrm{s} \\
& V w 1=V t \times \cos \beta 1=3.91 \mathrm{~m} / \mathrm{s} \\
& \alpha 1=\tan ^{-1}(V f 1 \div(V w 1-U 1))=28.02^{\circ}
\end{aligned}
$$

$\left(30^{\circ}\right.$ chosen for fabrication convenience) 


\section{Calculations at outlet}

$$
\begin{aligned}
& U 2=\pi \times I D \times N t \div 60=1 \mathrm{~m} / \mathrm{s} \\
& V 2=V f 1=V f 2=1.12 \mathrm{~m} / \mathrm{s} \\
& \alpha 2=\tan ^{-1}(V f 2 \div U 2)=48^{\circ}\left(45^{\circ} \text { chosen for fabrication convenience }\right) \\
& V w 2=V t \times \cos \beta 2=0
\end{aligned}
$$

\section{Calculation of theoretical power}

$$
P_{0}=\oint \times Q \times g \times H=66 \mathrm{~W}
$$

\section{Calculation of theoretical efficiency}

$$
\mathrm{y}_{h}=(V w 1 \times U 1) \div(g \times H)=92.14 \%
$$

\section{Calculation of radius of curvature}

$$
R=\left(O D^{2}-I D^{2}\right) \div(2 \times O D \times \cos \beta 1)=35 \mathrm{~mm}
$$

\section{Blade Design Summary}

\begin{tabular}{|c|l|c|c|}
\hline S.No. & Parameters & Symbols & Design values \\
\hline 1 & Blade inlet angle & $\alpha 1$ & $30^{\circ}$ \\
\hline 2 & Blade outlet angle & $\alpha 2$ & $45^{\circ}$ \\
\hline 3 & Radius of curvature & $\mathrm{R}$ & $35 \mathrm{~mm}$ \\
\hline 4 & Blade length & $\mathrm{L}$ & $80 \mathrm{~mm}$ \\
\hline 5 & No. of blades & $\mathrm{n}$ & 3,6 and 12 \\
\hline
\end{tabular}

The above calculations are for the first turbine. For the second turbine, the blade length was increased to $200 \mathrm{~mm}$ keeping blade inlet and outlet angles same as the first turbine. The radius of curvature(R) increased to $88 \mathrm{~mm}$.

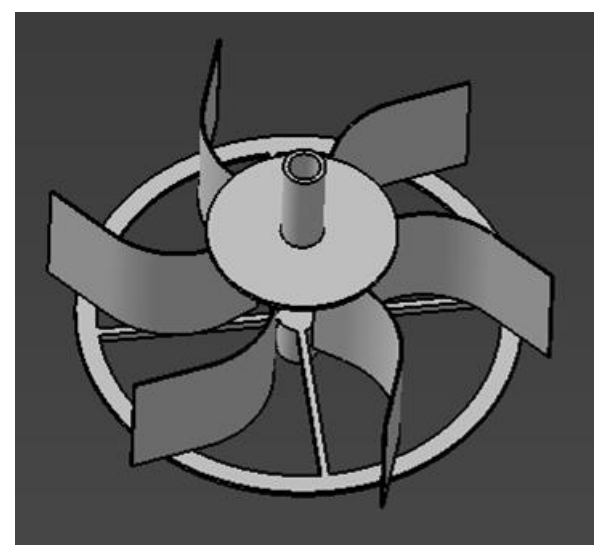

Figure 1: turbine designed in CATIA V5 


\section{Basin Design Calculations}

The basin inlet diameter for the conical basin is $600 \mathrm{~mm}$. This is the required diameter of the orifice was calculated to be $101.78 \mathrm{~mm}$ (100mm assumed for ease of fabrication).

Optimum vortex strength occurs within the range of orifice diameter to tank diameter ratios (d/D) of 14\% - 18\% for low and high head sites respectively [11].

For $\mathrm{d}=100 \mathrm{~mm}, \frac{d}{D}=16 \%$, which is reasonably close to the value for which the optimum vortex strength occurs.

The base of the basin however should be greater than this value so that the orifice diameter can be adjusted for experimental tests.

\section{Shaft Design}

$$
d=\left[\frac{16}{\pi \tau}\left\{\sqrt{\left(c_{m} \times M+\frac{\alpha F d}{8}\right)^{2}+\left(c_{t} \times T\right)^{2}}\right\}\right]^{\frac{1}{3}}
$$

Thediameter was calculated to be $0.03 \mathrm{~m}$ i.e. $30 \mathrm{~mm}$ [8].

\section{Stress analysis}

The stress analysis of the turbine blades and shaft was carried out in the Generative Structural Analysis workbench of CATIA V5.

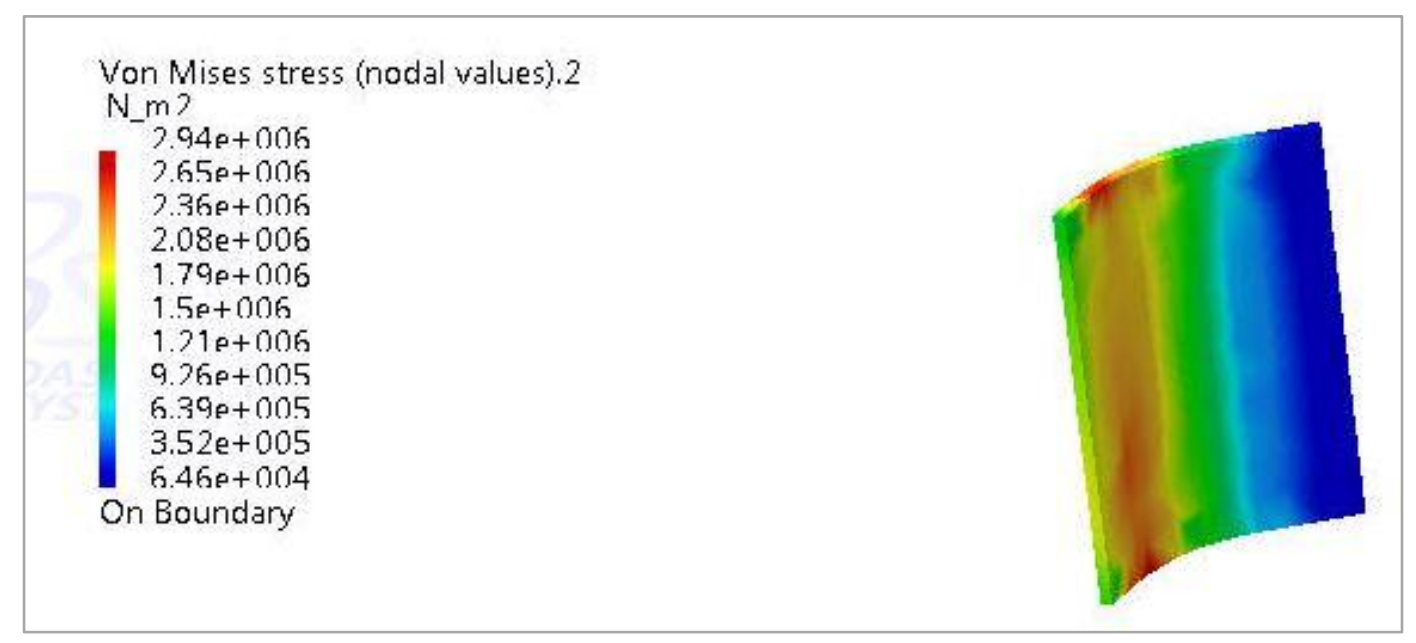

Figure 2: Stress analysis of runner blade 


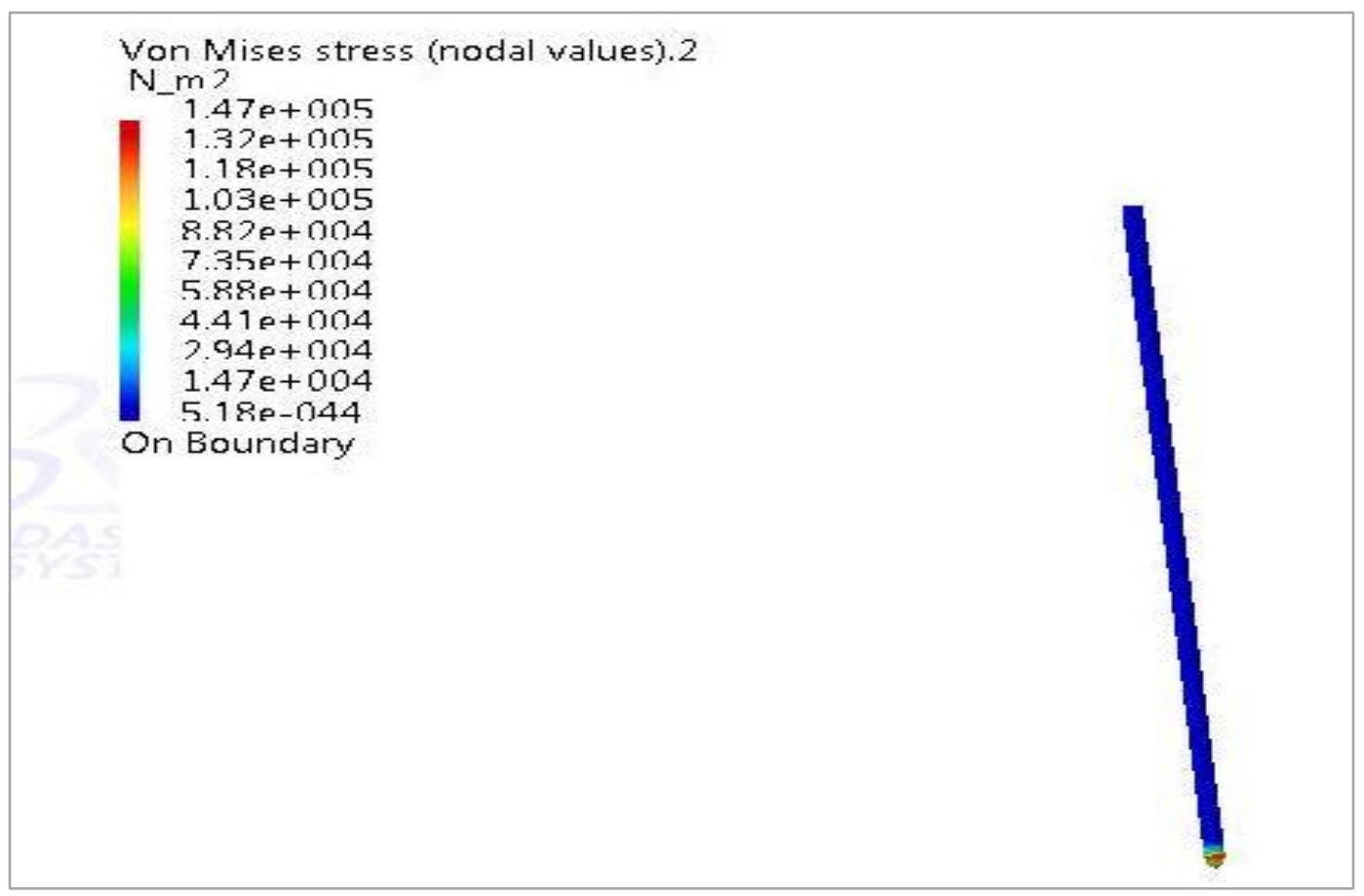

Figure 3: Stress analysis of shaft

\section{Measuring Equipment}

Measurement of torque and rpm was essential part of testing. For the measurement of torque produced by the turbines, Prony Brake was used with two springs, a rope and weights. Measurement of rpm was done by digital tachometer. The flow rate was measured by measuring the height of the $90^{\circ} \mathrm{V}$-notch.

\section{Measurement and Calculation}

\section{Vortex Measurement and Data Analysis}

$\begin{array}{llll}\text { Discharge } & : 8.63 \mathrm{LPS} & \text { Basin Height } & : 850 \mathrm{~mm} \\ \text { Exit hole diameter } & : 110 \mathrm{~mm} & \text { Basin diameter } & : 600 \mathrm{~mm}\end{array}$

Depth of water level from top of basin: $115 \mathrm{~mm}$ 


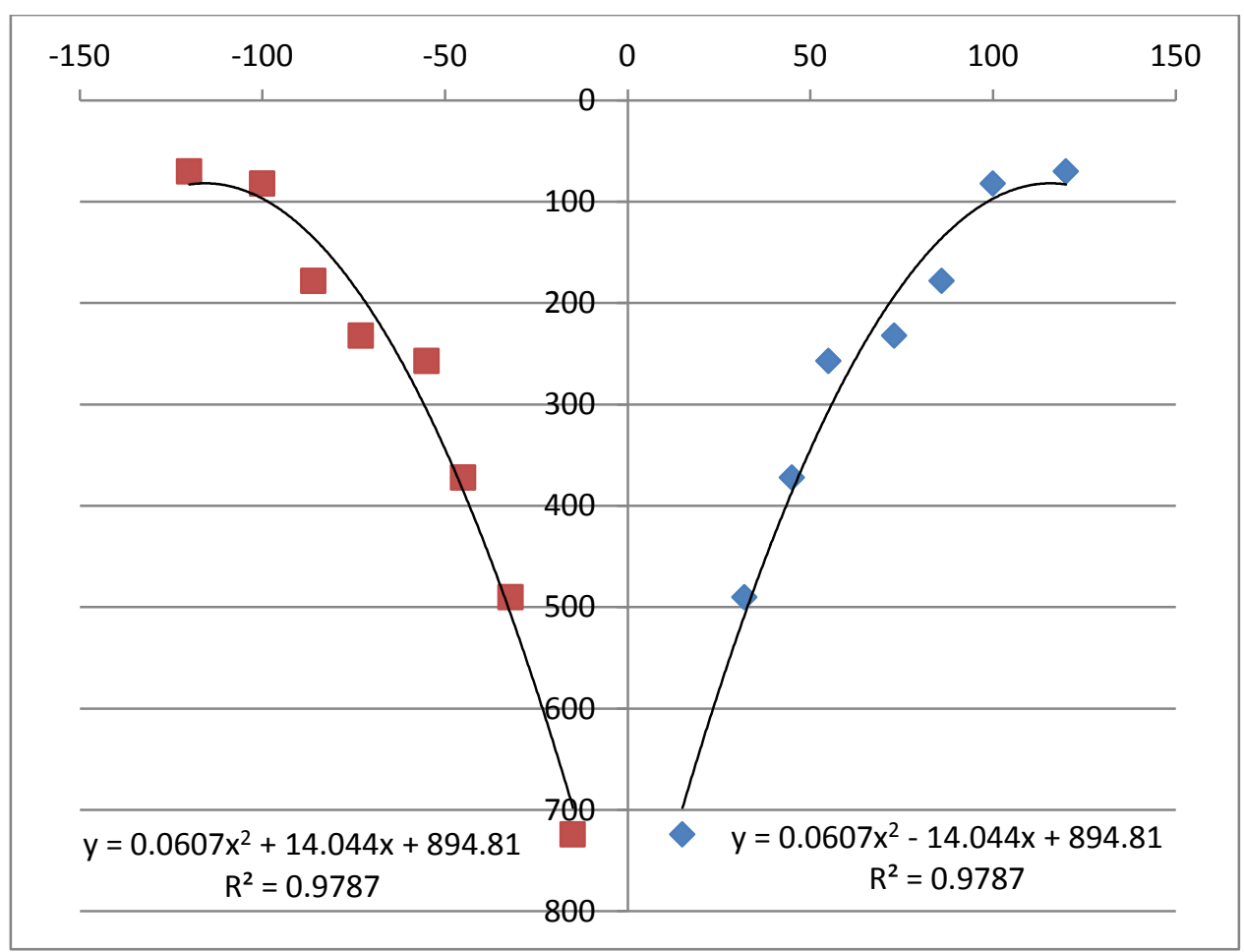

Figure 4: Vortex Profile for Cylindrical Basin

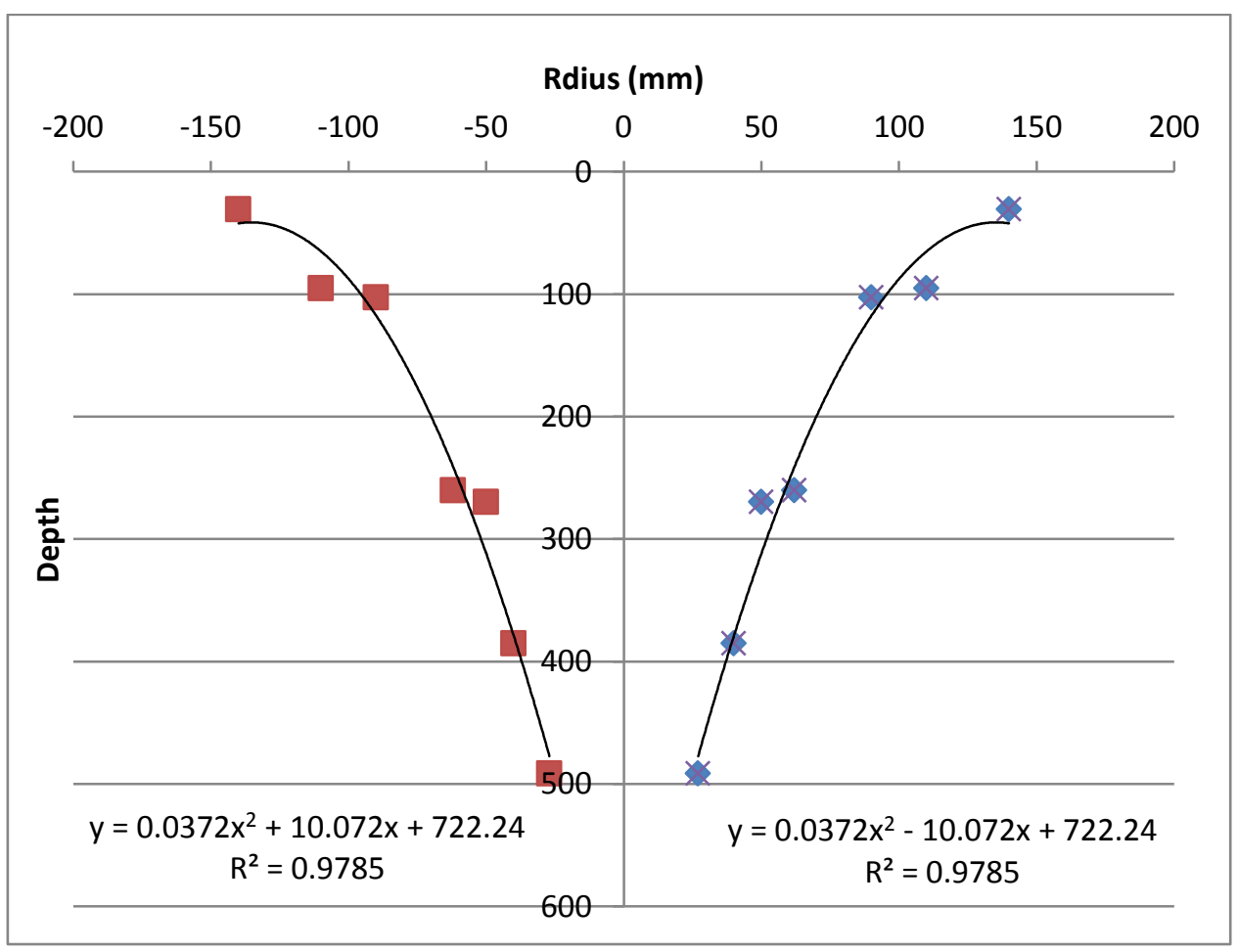

Figure 5: Vortex Profile for Conical Basin 
Table 1: Maximum efficiency obtained at each Test (cylindrical basin)

\begin{tabular}{|c|c|c|c|c|c|c|c|c|c|}
\hline $\begin{array}{c}\text { Test } \\
\text { no. }\end{array}$ & FW & Ff & $\begin{array}{c}\mathrm{F} \\
(\mathrm{kg})\end{array}$ & $\begin{array}{c}\mathrm{F} \\
(\mathrm{N})\end{array}$ & $\begin{array}{c}\mathrm{T} \\
(\mathrm{N}-\mathrm{m})\end{array}$ & $\begin{array}{c}\mathrm{N} \\
(\mathrm{rpm})\end{array}$ & $\begin{array}{c}\mathrm{P} \\
(\mathrm{W})\end{array}$ & $\begin{array}{c}\text { Po } \\
(\mathrm{W})\end{array}$ & $\begin{array}{c}\mathrm{D} \\
(\%)\end{array}$ \\
\hline 1 & 1.31 & 0.28 & 1.03 & 10.10 & 1.11 & 142 & 16.53 & 68.60 & 25.36 \\
\hline 2 & 5.52 & 2.35 & 3.17 & 31.10 & 1.55 & 103 & 16.77 & 68.60 & 24.45 \\
\hline 3 & 5.38 & 2.3 & 3.08 & 30.21 & 1.51 & 95.2 & 15.06 & 68.60 & 22.80 \\
\hline 4 & 3.25 & 1.49 & 1.76 & 17.27 & 0.86 & 112 & 10.13 & 68.60 & 15.33 \\
\hline 5 & 3.21 & 1.35 & 1.86 & 18.25 & 0.91 & 113 & 10.80 & 68.60 & 16.34 \\
\hline 6 & 2.44 & 0.82 & 1.62 & 15.89 & 0.79 & 115 & 9.57 & 68.60 & 14.49 \\
\hline 7 & 5.9 & 2.7 & 3.2 & 31.39 & 1.57 & 68 & 11.18 & 68.60 & 16.92 \\
\hline 8 & 3.08 & 1.2 & 1.88 & 18.44 & 0.92 & 89 & 8.59 & 68.60 & 13.01 \\
\hline 9 & 4.56 & 1.6 & 2.96 & 29.04 & 1.45 & 58 & 8.82 & 68.60 & 13.35 \\
\hline 10 & 7.5 & 3.6 & 3.9 & 38.26 & 1.91 & 36 & 7.21 & 68.60 & 10.51 \\
\hline 11 & 5.56 & 2.8 & 2.76 & 27.08 & 1.35 & 59.8 & 8.48 & 68.60 & 12.36 \\
\hline 12 & 6.54 & 3.2 & 3.34 & 32.77 & 1.64 & 66.8 & 11.46 & 68.60 & 16.71 \\
\hline
\end{tabular}

Test 1, 2 and 3 were taken with turbine1 (with blade number 6) at bottom, middle and upper part of basin respectively. Test 4, 5 and 6 were taken with turbine1 with blade number 12 (6 more blades were added in turbine1) at bottom, middle and upper part of basin respectively.

Test 7, 8 and 9 were taken with turbine2 (with blade number 3) at bottom, middle and upper part of basin respectively. Test 10,11 and 12 were taken with turbine2 (with blade number 6) at bottom, middle and upper part of basin respectively.

Above data shows that the best position for obtaining maximum power is at the bottom of the basin. Increasing the number of blades reduced power as in case of first turbine. It may be because of increase in weight due to the addition of blades.

Table 2: Maximum efficiency obtained with conical basin

\begin{tabular}{|c|c|c|c|c|c|c|c|c|c|}
\hline $\begin{array}{c}\text { Test } \\
\text { no. }\end{array}$ & Fw & Ff & $\begin{array}{c}\mathrm{F} \\
(\mathrm{kg})\end{array}$ & $\begin{array}{c}\mathrm{F} \\
(\mathrm{N})\end{array}$ & $\begin{array}{c}\mathrm{T} \\
(\mathrm{N}-\mathrm{m})\end{array}$ & $\begin{array}{c}\mathrm{N} \\
(\mathrm{rpm})\end{array}$ & $\begin{array}{c}\mathrm{P} \\
(\mathrm{W})\end{array}$ & $\begin{array}{c}\text { Po } \\
(\mathrm{W})\end{array}$ & $\begin{array}{c}\mathrm{D} \\
(\%)\end{array}$ \\
\hline 1 & 5.75 & 2.75 & 3 & 29.43 & 1.47 & 127 & 19.57 & 66.05 & 29.6 \\
\hline 2 & 5.62 & 2.45 & 3.17 & 31.10 & 1.55 & 101.8 & 16.58 & 66.05 & 25.1 \\
\hline
\end{tabular}

Test 1 and 2 were taken with turbine1 (with blade number 12) at middle and upper part of conical basin respectively. The efficiency of the system is higher with conical basic than cylindrical for same turbine at same position. 


\section{Site Testing}

After several tests in the test rig, a site test was carried out in the ManoharaRiver located at Pepsicola, Kathmandu. The primary purpose of the site test was to briefly assess the possibility of power generation from a local river with low head.

\section{Vortex Strength Comparison}

\begin{tabular}{|c|c|c|c|c|c|}
\hline Radius & $\begin{array}{c}\text { Depth } \\
\text { (cylindrical) }\end{array}$ & $\begin{array}{c}\text { Depth } \\
\text { (conical) }\end{array}$ & $\begin{array}{c}\text { Vortex strength } \\
\text { K } \\
\text { (cylindrical) }\end{array}$ & $\begin{array}{c}\text { Vortex strength } \\
\text { K } \\
\text { (conical basin) }\end{array}$ & $\begin{array}{c}\% \\
\text { difference }\end{array}$ \\
\hline 5 & 826.1 & 672.81 & $3.282 \mathrm{E}-04$ & $4.030 \mathrm{E}-04$ & 22.784 \\
\hline 10 & 760.4 & 625.24 & $7.131 \mathrm{E}-04$ & $8.672 \mathrm{E}-04$ & 21.617 \\
\hline 15 & 697.7 & 579.53 & $1.166 \mathrm{E}-03$ & $1.403 \mathrm{E}-03$ & 20.391 \\
\hline 20 & 638 & 535.68 & $1.700 \mathrm{E}-03$ & $2.024 \mathrm{E}-03$ & 19.101 \\
\hline 25 & 581.3 & 493.69 & $2.332 \mathrm{E}-03$ & $2.746 \mathrm{E}-03$ & 17.746 \\
\hline 30 & 527.6 & 453.56 & $3.083 \mathrm{E}-03$ & $3.587 \mathrm{E}-03$ & 16.324 \\
\hline 35 & 476.9 & 415.29 & $3.980 \mathrm{E}-03$ & $4.570 \mathrm{E}-03$ & 14.835 \\
\hline 40 & 429.2 & 378.88 & $5.053 \mathrm{E}-03$ & $5.725 \mathrm{E}-03$ & 13.281 \\
\hline 45 & 384.5 & 344.33 & $6.346 \mathrm{E}-03$ & $7.086 \mathrm{E}-03$ & 11.666 \\
\hline 50 & 342.8 & 311.64 & $7.909 \mathrm{E}-03$ & $8.700 \mathrm{E}-03$ & 9.999 \\
\hline
\end{tabular}

This comparison table indicates that vortex strength is greater in the conical basin than the cylindrical basin and hence the performance too.

\section{Conclusion and Recommendations}

\section{Conclusion}

Two turbines with different number of blades and blade radii were tested by measuring torque and rpm. The measurements indicated that the best position for the placement of turbine is the bottommost position. The value of velocity head increases with the increase in depth. Hence greater efficiency was noted at the bottommost position.

Similarly, the values of efficiency were greater for turbines with smaller number of blades. There was a significant distortion of vortex even with smaller loads in case of the turbine configuration with greater number of blades. Also, increase in the radius of the blades decreases the efficiency of turbines. This is because of friction at the inner surface of the basins.

Strength comparison between the vortexes formed with conical and cylindrical basins shows that vortex formation was aided by conical basin. Use of conical created a significant increase in vortex strength as shown in the vortex strength comparison table. Tests of the same turbine on conical basin provided the maximum efficiency of $29.63 \%$ which is significantly greater than the 
values provided by all the tests on cylindrical basin. Hence it is preferable to use conical basins for gravitational water vortex turbines.

\section{Recommendations}

- Tests should be carried out by varying flow rates on a different test rig.

- Turbine fabrication should be carried out using better materials for weight reduction and increase in structural strength.

- Canal and notch angle optimization should be carried out to obtain better vortex in the basins.

- Tests should be carried out by changing the exit hole diameter to optimize the conical basin.

\section{Nomenclature}

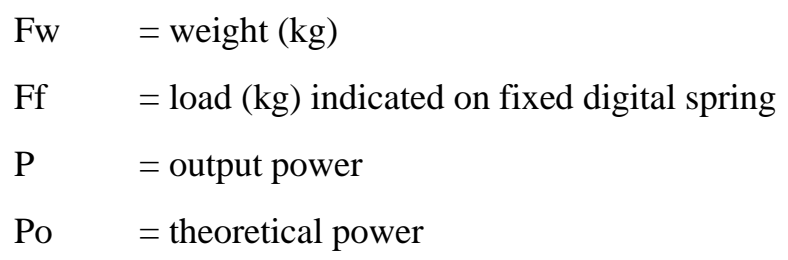

\section{References}

[1] Zotloterer. (2013). Retrieved December 2012, from Zotloterer website: www.zotloterer.com.

[2] Chaulagain, R. K. (2012). Development and Testing of Gravitational Water Vortex Turbine. IOE.

[3] Faulkner, S. (1991). A simplified low head propeller turbine for micro-hydro electric power.

[4] Fox, R. W., Pritchard, P. J., \& McDonald, A. T. (2008). Introduction to Fluid Mechanics. Wiley India.

[5] Grewal, B. S. (2011). Numerical Methods.

[6] Harvey, A. (1993). Micro-hydro Design Manual. London: IT Publications.

[7] Lal, J. (2009). Hydraulic Machines. Metropolitan Books.

[8] Mahadevan, K., \& Reddy, K. B. (2011). Design Data Handbook For Mechanical Engineers.

[9] Mathis, D. (2012). Fundamentals of Turbine Design.

[10] Merryfield, F., \& Mockmore, C. A. (1949). The Banki Water Turbine.

[11] Mulligan, S., \& Hall, P. (2010). Design and Optimization of Water vortex power plant.

[12] Patrick Ho-Yan, B. (2012). Design of a Low Head Pico Hydro Turbine for Rural Electrification in Cameroon.

[13] Singh, P., \& Nestmann, F. (2009). Experimental optimization of a free vortex propeller runner for microhydro application.

[14] Venkatesan, S. (2012). Measurement of Force or Acceleration Torque and Power. 